\title{
Payments in planned HIV trial raise ethical concerns
}

An unusual HIV-prevention trial planned to take place in rural Tanzania has sparked questions from ethicists. In the proposed trial, approximately 3,000 Tanzanians between the ages of 15 and 30 are slated to receive monthly cash payments of $\$ 45$ as an incentive to avoid diseases transmitted through unsafe sex. That's serious money in a nation where, in 2006, the World Bank put per capita income at $\$ 350$.

Bioethicists say that any ethics committee signing off on the trial must address the question of coercion. By paying $\$ 45$ monthly in a country as poor as Tanzania, "are you paying them so much that they can't refuse your offer?" asks Arthur Caplan, a bioethicist at the University of Pennsylvania in Philadelphia.

Researchers from the Ifakara Health Research and Development Centre (IHRDC) in southeastern Tanzania plan to conduct the trial in conjunction with scientists from the University of California system. On the IHRDC website, researchers trumpet the trial's "conditional cash transfers" approach as "a big advance in efforts to test public health ideas more rigorously" and note that some participants in a control arm will not be offered payments.

Testing for other sexually transmitted diseases will serve the trial as a proxy for determining HIV infection status. IHRDC researchers declined to elaborate further on the proposed trial when contacted by Nature Medicine.

The proposed three-year trial could potentially receive funding support from the World Bank. But Eric Chinje, manager of communications for the region of Africa at the World Bank, says that the institutions involved are still assessing the trial and "there is no consensus on its viability."

Karen Maschke, who focuses on ethics and science policy at the Hastings Center in Garrison, New York, points out that the behavior being encouraged by the payments is not entirely risk-free: "In some conditions, you are putting women at risk [of violence] for demanding safety during sex."

Bioethicist Stuart Rennie of the University of North Carolina at Chapel Hill agrees that the trial raises a list of issues, including the practical concern of how to keep a new infection confidential in a family counting on the income from the trial. Still, he says, the trial has clinical promise: "I think they should pilot it."

There is some precedent for cash incentive programs, albeit not involving sexual practices: In Mexico in the late 1990s, a government-sponsored program boosted class attendance significantly by offering cash rewards to poor families that sent their children to school. And, in the United States, a growing number of states provide financial incentives to encourage people receiving
Medicaid to use preventive services and combat smoking and obesity. Whether these US interventions are effective, however, has not been proven in rigorous studies.

Meredith Wadman, Washington, DC

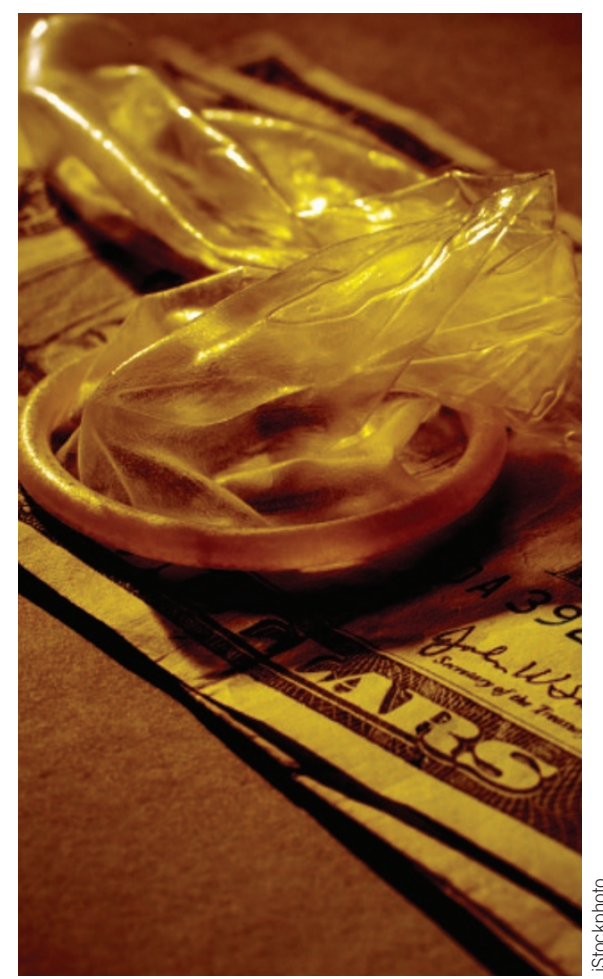

Precaution pays: Cash incentives considered

\section{New effort seeks to unravel the mystery of undiagnosed disease}

To win a battle, soldiers must have a good sense of their adversary. But for people with mysterious diseases that defy diagnosis, the enemy remains unknown. To address this challenge, the US National Institutes of Health (NIH) plans to launch a center that brings together a team of $25 \mathrm{NIH}$ multidisciplinary experts to evaluate and treat patients at its Clinical Center.

The new Undiagnosed Diseases Program, announced on 19 May, will bring together specialists from the NIH Clinical Center as well as the country's National Human Genome Research Institute (NHGRI) and the Office of Rare Diseases. Until now, people with rare, undiagnosed diseases had no central site at the $\mathrm{NIH}$ to turn to for diagnosis and treatment.

Excluding cases of undiagnosed illnesses, more than 6,000 known rare medical conditions affect a total of 25 million people in the United States alone. Many individuals with such ailments show a baffling collection of symptoms involving multiple organ systems or have rare, unknown subtypes of known diseases, says NIH director Elias Zerhouni.

"These are abandoned disorders, about which the medical profession has given up," says NHGRI clinical director William Gahl. "By default, many are considered psychiatric disorders when there might in fact be an underlying, undiagnosed physical disorder."

Take, for example, the case of 26-year-old Amanda Young, whose rare genetic immune disorder took longer than a decade to diagnose, during which time she suffered many lifethreatening infections, surgeries and a leg amputation. When she first began developing symptoms as a child-frequent, intractable infections - this pathway and the mutation was unknown, Gahl explains. NIH scientists have since pinned her weakened immune system on a mutation in the IRAK4 gene and hope that such discoveries will help bring them closer to providing effective treatment.

With only $\$ 280,000$ of funding annually for three paid staff members (two nurse practitioners and a scheduling assistant), the program will draw on the expertise of NIH scientists, who will, as a team, review an estimated two cases a week. As well as treatment, the program's other goal is to develop new diagnostic algorithms and, ultimately, new diagnostics.

"We are encouraged and excited by this first step toward coordinated care for patients who may never receive a diagnosis," says Mary Dunkle of the National Organization of Rare Diseases, a patient advocacy group based in Danbury, Connecticut. "This gives us a place to start-a place to send patients who call us for help."

Vicki Brower, New York 